\title{
Correction to: Risk-aware business process management using multi-view modeling: method and tool
}

\author{
Rafika Thabet $^{1,2}$ (D) Dominik Bork ${ }^{3,4}$ - $\cdot$ Amine Boufaied ${ }^{1} \cdot$ Elyes Lamine $^{5,6} \cdot$ Ouajdi Korbaa $^{1} \cdot$ Hervé Pingaud $^{2}$
}

Published online: 20 May 2021

๑) Springer-Verlag London Ltd., part of Springer Nature 2021

\section{Correction to: Requirements Engineering https://doi.org/10.1007/s00766-021-00348-2}

In the original publication of the article, several citation errors were present.

The correct reference sections should read as below.

1. The citation [67] should point to the 22nd entry in the reference list. Any occurrence of [67] should have been replaced with a reference to [22].

2. Every citation in the text with a reference number from [22] to [66] should reference to the reference with the same number +1 . All references from [22] to [66] should be corrected by adding 1 to the number. For example, the reference to [46] in the text should instead refer to the 47th entry in the reference list, i.e. replacement of [46] by [47].

Publisher's Note Springer Nature remains neutral with regard to jurisdictional claims in published maps and institutional affiliations.
The original article can be found online at https://doi.org/10.1007/ s00766-021-00348-2.

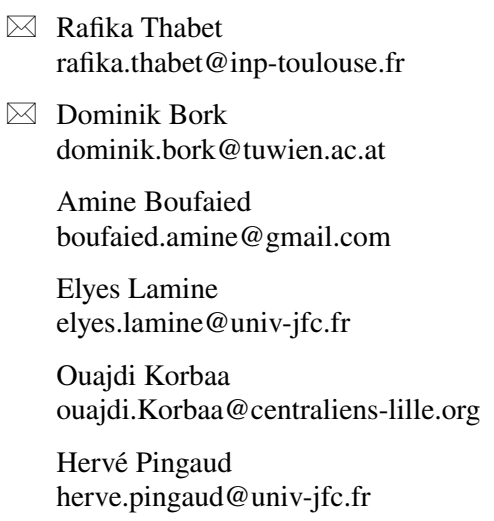

1 ISITCom, MARS Research Lab, University of Sousse, Route G.P.1, 4011 Hammam Sousse, Tunisia

2 INP, CNRS, LGC, University of Toulouse, 31432 Toulouse Cedex 04, France

3 Business Informatics Group, TU Wien, Vienna, Austria

4 Faculty of Computer Science, University of Vienna, Vienna, Austria

5 ISIS, Institut National Universitaire Champollion, University of Toulouse, Rue Firmin-Oulès, 81104 Castres, France

6 Department of Industrial Engineering, IMT Mines Albi, Route de Teillet, 81013 Albi Cedex 9, France 